\title{
Transmission Line Collaborative Evaluation Index Inspection Benefit Set
}

\author{
Jing $\mathrm{Xu}^{1, \mathrm{a}}$, Hanning $\mathrm{Fu}^{1, \mathrm{~b}}$, Jingping $\mathrm{Li}^{2, \mathrm{c}}$ and Zhongfu $\mathrm{Qin}^{2, \mathrm{~d}^{*}}$ \\ ${ }^{1}$ National Network Maintenance Subsidiary Zhejiang Electric Power Corporation, Hangzhou, \\ Zhejiang, China, 310007 \\ ${ }^{2}$ Zhejiang University Institute of Architectural Engineering, Hangzhou, Zhejiang, China, 310058 \\ a282898098@qq.com, ${ }^{b} 852601167 @ q q . c o m,{ }^{\circ} 980322 @ 163 . c o m,{ }^{d}$ qinzhongfu@zju.edu.cn
}

Keywords: Cooperative inspection; Impact factor; Benefit evaluation

\begin{abstract}
In recent years, with the continuous expansion of the transmission network, power grid operation maintenance line mileage rapid growth and power network operation maintenance relatively insufficient number of personnel between the contradictions appear gradually, is bound to promote the power grid operation and maintenance from labor intensive to technology intensive change. A new inspection mode, artificial helicopters, UAV cooperation is an urgent need for the development of smart grid. Through the analysis of characteristics of these single inspection mode, this study, as well as two or more than two kinds of inspection mode complementary mechanism and characteristic analysis based on, to tease out the cooperative inspection efficiency influence factor, and won the synergy inspection benefit evaluation model of evaluation index.
\end{abstract}

\section{Introduction}

With the increasing expansion of power grid, power lines and equipment not only bear the mission of daily mechanical load and power load, but they also suffer long-term exposure to the external environment such as lightning, strong winds, floods and other external forces. Therefore, as an important part of the work of the power sector, power equipment inspection is an important process to ensure the normal operation of power facilities. Considering the increasing length of transmission lines and increasingly complex external environment, there are higher requirements on transmission line operation inspection; traditional ground manual inspection can no longer meet the requirements; developing helicopter and unmanned aerial inspection has become an inevitable trend. We know that a single inspection mode has its inevitable shortcomings. Therefore, it is consistent with the development of the society to carry out synthetic inspection, combining the advantages of various inspection models, and carry out inspections of daily operation, failures and emergencies of the transmission lines. Therefore it is urgent that we carry out benefit assessments of the synthetic inspection of transmission lines; it is also important to make cost-efficiency assessments of synthetic inspection before implementing the assessments of coordinated inspection.

Overhead transmission lines cover a wide range of areas through complex terrains of sometimes terrible natural conditions; thus the maintenance requirement is going up. As transmission facilities are exposed outside, in order to control their operation and respond to failures, deficiencies and hazards timely, every year huge amounts of human and material resources are invested into line inspections. From traditional ground manual inspections to the helicopter and unmanned aerial inspections that are gradually being applied and promoted, the inspection models are being more diversified [1]. The increasing length of transmission lines and ever more complicated external environment raise a higher requirement for line operation inspections. Traditional ground manual inspections can no longer meet the requirements; developing helicopter and unmanned aerial inspection has become an inevitable trend [2]. With the development of transmission expertise and helicopter and unmanned plane technologies, China's line inspection models are increasingly diversified, including traditional ground manual inspections, regularized helicopter inspections carried out in recent years and unmanned inspections to be put into practice. However, there is no 
unified regulation on the above three models; they are carried out independently, which raises the cost of line inspections [2].

Manual ground work is the main model of transmission line inspections in China, complemented by helicopter inspection; unmanned aerial inspection is still in its infancy. One manual inspection is carried out per month and one helicopter inspection is carried out every one to three years. Unmanned aerial inspections will be carried out based on specific needs. Under specific conditions such as special power supply periods, the frequency of ground and helicopter inspections will be increased [3]. In 2013, China Southern Power Grid began its plan to implement a working mechanism centered around helicopter inspections complemented by manual inspections in an attempt to streamline line maintenance[4].In order to streamline management and reduce operation costs of overhead transmission lines and standardize inspection models, many Chinese experts such as $\mathrm{Xu}$ Yunpeng have discussed and studied the complementary mechanism of helicopter, unmanned plane and manual inspections from the perspectives of voltage levels, inspection tasks, inspection areas, inspection terrains, inspection coordination cycles, etc. An efficient and new transmission operation model has been established [5].

Helicopter inspection is the main model of transmission line inspections outside China, complemented by unmanned aerial and manual inspections [6-7]. For example, French power grid companies conduct normal helicopter inspections once a year, complemented with ground manual inspections once every 15 years. In Singapore normal helicopter inspections is carried out once a year [8-10].

This research studies the influencing factors of the cost-efficiency of each inspection model, based on which an analysis is made of the indicators of the cost-efficiency assessments of the final synthetic inspection. As the influencing factors of the three models-helicopter, unmanned plane and ground manual work - are different but overlapping, this research examines them separately, and summarizes their common factors through discussions and demonstrations. The reason is that only the common factors of synthetic inspections can effectively distinguish specifically which synthetic model can maximize benefits under a certain circumstance.

\section{Analysis on the Factors Influencing Collaborative Inspection Efficiency}

Extraction of the Factors Influencing Collaborative Inspection Efficiency. Based on relevant materials, conducting theory study, consulting to the experts in the field of electricity and carrying out brainstorm, this study extracts the factors which influence collaborative inspection efficiency of transmission line as follow:

Topographic Factors. In the set up of transmission line, the topographic factors are usually the key in the selection of the way in set up. The topographic factors mainly include three types of terrain: plain, hills, mountains and rivers.

Distance Factors. The distance of inspection here mainly covers two factors, including the transportation distance of the vehicle and human in every 100 miles. The transportation distance of the vehicle and human will have direct impact on the cost of collaborative inspection.

The Height of Tower. In general, there are three kinds of height of transmission line tower: under $40 \mathrm{~m}, 40-70 \mathrm{~m}$ and over $70 \mathrm{~m}$. If there is need to inspect by climbing the tower, the height of tower will obviously have impacts on the efficiency of collaborative inspection to some degree.

The Type of Tower. There are many types of tower, while the tangent tower and strain tower are used more widely than others. The efficiency of inspection on these two towers is also different.

The Number of Towers Each 100 Miles. The number of tower base on each 100 miles tends to directly affect specifications like time and quality in collaborative inspection. Therefore, it will exert great influence on the efficiency of collaborative inspection.

The Vegetation Factor. The difference of vegetation tends to have direct impact on the results of collaborative inspection. This study classifies vegetation factors into following types: lawn, bare 
land, mountain forest and bush. The difference in the layout of vegetation will directly influence the speed, quality and safety of collaborative inspection, and thus affecting the efficiency of collaborative inspection.

The Types of Inspection. The collaborative inspection of power grid is usually classified into three kinds: daily inspection, emergency inspection and malfunction inspection. Each of them has different cost, and the same is true of the efficiency of collaborative inspection.

The Way of Working. The way of working mainly contains walking and climbing the pole. The time and cost consumed in these two ways are different, and the same of is true of the results of collaborative inspection.

The Factors of Weather. The factors of weather mainly consist of circumstances in spring and autumn, summer, winter, storm and snow. All these factors will have impact on the quality, safety, efficiency and cost of collaborative inspection, and then further influence the efficiency of collaborative inspection.

Skill Experience. Workers with competent experience have higher inspection efficiency than those with less experience.

The Way of Inspection. Collective segment is the main way used in current manual inspection of transmission line. As the number of workers in inspection will have impacts on the speed, cost and safety of inspection, the way used in inspection is also an important factor for the efficiency of collaborative inspection.

The Object of Inspection. The objects of inspection usually are the "body" and "channel". As the efficiency, safety factor and cost are various for different objects, the efficiency of collaborative inspection are also different with the changing of objects.

The Factor of Traffic Condition. The traffic condition of the efficiency of collaborative inspection mainly refers to the condition of highway used by vehicle and pedestrians in the process of collaborative inspection, such as the influence of highway grade on the transportation distance of vehicles. Vehicle and manual transportation distance tend to be affected by the traffic conditions. Vehicle and manual transportation distance will directly change the cost of collaborative inspection, and then affect the efficiency of collaborative inspection.

Geological Factor. The main geological factors discussed here are mineral and geological structure. The basic forms of geological structure are fracture and fold. According to experts in this field, the geological conditions will exert influence on the defect identification and channel inspection, and then affect the efficiency of collaborative inspection.

The Continuity of Inspection. It mainly includes continuous inspection and interval inspection. The efficiency of these two kinds of inspection is different, and then the efficiency of inspection is also affected by it. However, the reasons are not definite yet.

The Frequency of Malfunction. It refers to the frequency of breakdown of transmission line, and directly reflects the efficiency of inspection. The frequency of malfunction is the results influenced by the factors rather than the factor affecting the efficiency of collaborative inspection.

Comprehensive Assessment. According to experts, this factor includes applicability, convenience of control and so on. If there is comparison between collaborative inspection and unmanned airplane inspection, the comprehensive assessment will then be a significant factor in choosing inspection methods.

The Body Factor. This factor focuses on the height of tower (under 40m, 40-70m and over 70m), the types of tower (tangent tower and strain tower), circuit number and division number of lines. The body is the object of inspection. Different objects consumes different time and cost.

Weight. The specification with different weight in constituting the efficiency will affect the results of the efficiency of collaborative inspection.

Effect: the effect of transmission line inspection generally means the recognition rate of defects. Being based on adequate consultation to relative experts, the study classifies defects into the recognition rates of noumenon, passage and fault. The effect of collaborative inspection is the direct 
influential factor of collaborative inspection efficiency. The result of the inspection is the reference to the choice of inspection ways.

Connotations of quality, quality factor and effective factor are similar. There are subtle distinctions between quality and effect. The connotation of effect often contains quality and efficiency, etc. The study mainly focuses on malfunction dot rate and recognition rate of tower, transmission passage way and fault to examine the quality of collaborative inspection.

Safety: the study classifies indicators that affect the safety of collaborative inspection into safety of road transport, manual transport and safety of inspection by climbing the tower. All of these safety factors directly affect the efficiency of collaborative inspection.

Efficiency: combining the specific situations of inspecting transmission lines, the study divides the effect of inspection into efficiencies of vehicle transport, manual transport and of manual 1 inspection. The efficiency of inspection can be regarded as an important reference to inspection performance.

Cost: inspecting cost mainly includes direct cost and indirect cost. Direct cost covers the cost of vehicle transport and the cost of manual inspection. Whereas indirect cost includes the purchase fee of inspection equipment and its repair and maintenance fee, costs of equipment management, energy consumption, logistics, training program, software, communicating service and disposal of data(collection in early stage and disposal in later stage),etc. The cost reflects the economical efficiency of inspection and is also an important influential factor for inspection efficiency.

Distinguishing the Influencing Factors of the Cost-efficiency of Synthetic Inspections. 24 factors influencing synthetic inspections are extracted through the process mentioned above. After literature review, theoretical research and consultation with related experts in line inspection, the follow is the distinguishment of the extracted 24 factors; the principles and process of distinguishment are shown in Table 1. 
Table 1 Influencing factors of cooperative inspection work

\begin{tabular}{|c|c|c|c|c|c|}
\hline \multirow{2}{*}{$\begin{array}{l}\text { Before Adjustment } \\
\text { Landform Factor }\end{array}$} & \multirow{2}{*}{$\begin{array}{l}\text { After Adjustment } \\
\text { Topographic } \\
\text { condition }\end{array}$} & \multirow[t]{2}{*}{ Adjusting Ways } & \multicolumn{3}{|c|}{ Reasons for adjustments } \\
\hline & & & $\begin{array}{l}\text { Unify form } \\
\text { performance }\end{array}$ & on & Writing \\
\hline Distance factor & Inspection distance & Reserve & $\begin{array}{l}\text { Unify form } \\
\text { performance }\end{array}$ & on & Writing \\
\hline Tower height & Tower height & & & & \\
\hline Shape of tower & Shape of tower & & & & \\
\hline $\begin{array}{l}\text { Tower } \\
\text { Cardinality/Kilomete } \\
\text { rs }\end{array}$ & e Tower Cardinality & & $\begin{array}{l}\text { Unify form } \\
\text { performance }\end{array}$ & on & Writing \\
\hline Plant factor & Plant conditions & & $\begin{array}{l}\text { Unify form } \\
\text { performance }\end{array}$ & on & Writing \\
\hline $\begin{array}{l}\text { Inspection } \\
\text { classification }\end{array}$ & $\begin{array}{l}\text { Inspection } \\
\text { classification }\end{array}$ & & $\begin{array}{l}\text { Canonical form } \\
\text { performance }\end{array}$ & on & writing \\
\hline Inspection methods & Inspection methods & & & & \\
\hline Weather conditions & Weather conditions & & & & \\
\hline \multicolumn{6}{|c|}{ Technical experience Technical experience } \\
\hline Operation Modes & Operation Modes & & \multicolumn{3}{|c|}{ Important influence factor } \\
\hline \multicolumn{6}{|c|}{ Inspection objectives Inspection objectives } \\
\hline $\begin{array}{l}\text { Continuity } \\
\text { inspection }\end{array}$ & $\begin{array}{l}\text { f Continuity } \\
\text { inspection }\end{array}$ & & & & \\
\hline $\begin{array}{l}\text { Traffic conditions } \\
\text { factor }\end{array}$ & ${ }^{S}$ Traffic conditions & & $\begin{array}{l}\text { Unify form } \\
\text { performance }\end{array}$ & on & Writing \\
\hline Geological factors & & Delete & $\begin{array}{l}\text { Low incidence } \\
\text { probability }\end{array}$ & and & impact \\
\hline Failure frequency & & Reserve & $\begin{array}{l}\text { Belong to } \\
\text { classification }\end{array}$ & i) & nspection \\
\hline $\begin{array}{l}\text { Comprehensive } \\
\text { evaluation }\end{array}$ & $\begin{array}{l}\text { Comprehensive } \\
\text { evaluation }\end{array}$ & Reserve & Important influenc & facto & \\
\hline Weight & Weight & Constant & Important influenc & facto & \\
\hline Effect & & Merge & Combine with qual & lity fac & ctor \\
\hline Quality & Quality & Delete & $\begin{array}{l}\text { These four indexe } \\
\text { effects }\end{array}$ & d are & results of \\
\hline Safety & Safety & & & & \\
\hline Cost & Cost & & & & \\
\hline Effiency & Effiency & & & & \\
\hline Ontology Factor & Inspection Object & Merge & Combine with insp & ection & object \\
\hline
\end{tabular}


The results of classification of the influencing factors are shown in Table 2:

Table 2 The results of the classification of the impact factors of the cooperative inspection

\begin{tabular}{ll}
\hline First Level Influence Factors & Second Level Influence Factors \\
\hline Topographic condition & $\begin{array}{l}\text { Flat ground, mountain and hilly areas, } \\
\text { river }\end{array}$ \\
Weather conditions & Fine weather, heavy weather \\
Season Conditions & Spring, summer, autumn and winter \\
Tower height & Low tower, mid tower, High tower \\
Shape of tower & Linear tower, strained angled tower \\
Number of divisions & $1,2,4,6,8$ divisions \\
Circuit numbers & $\begin{array}{l}1,2,4 \text { circuits } \\
\text { Regular inspections, malfunction } \\
\text { inspections(three types), Emergency } \\
\text { inspections }\end{array}$ \\
\hline
\end{tabular}

\section{The Setting of Assessment Indicators of the Cost-efficiency of Synthetic Inspections}

The indicators are set based on the following principles

(1)Maximization of the difference among inspection models:

(2)Maximization of the difference among inspection tasks:

The research has obtained four indicators that can best reflect and comprehensively cover the cost-efficiency of synthetic inspections of transmission lines-quality, safety, efficiency and economics. The assessment that this research makes on the cost-efficiency of the synthetic inspections is exactly a comprehensive analysis based on these four indicators in order to evaluate the cost-efficiency of each synthetic model.

The assessment indicators are divided into three levels. Level One is the cost-efficiency mentioned before, consisting of four Level Two indicators-quality, safety, efficiency and economics, which also include different Level Three indicators. These are summarized into Table 3. 
Table 3 Efficiency evaluation index system of transmission line collaborative inspection

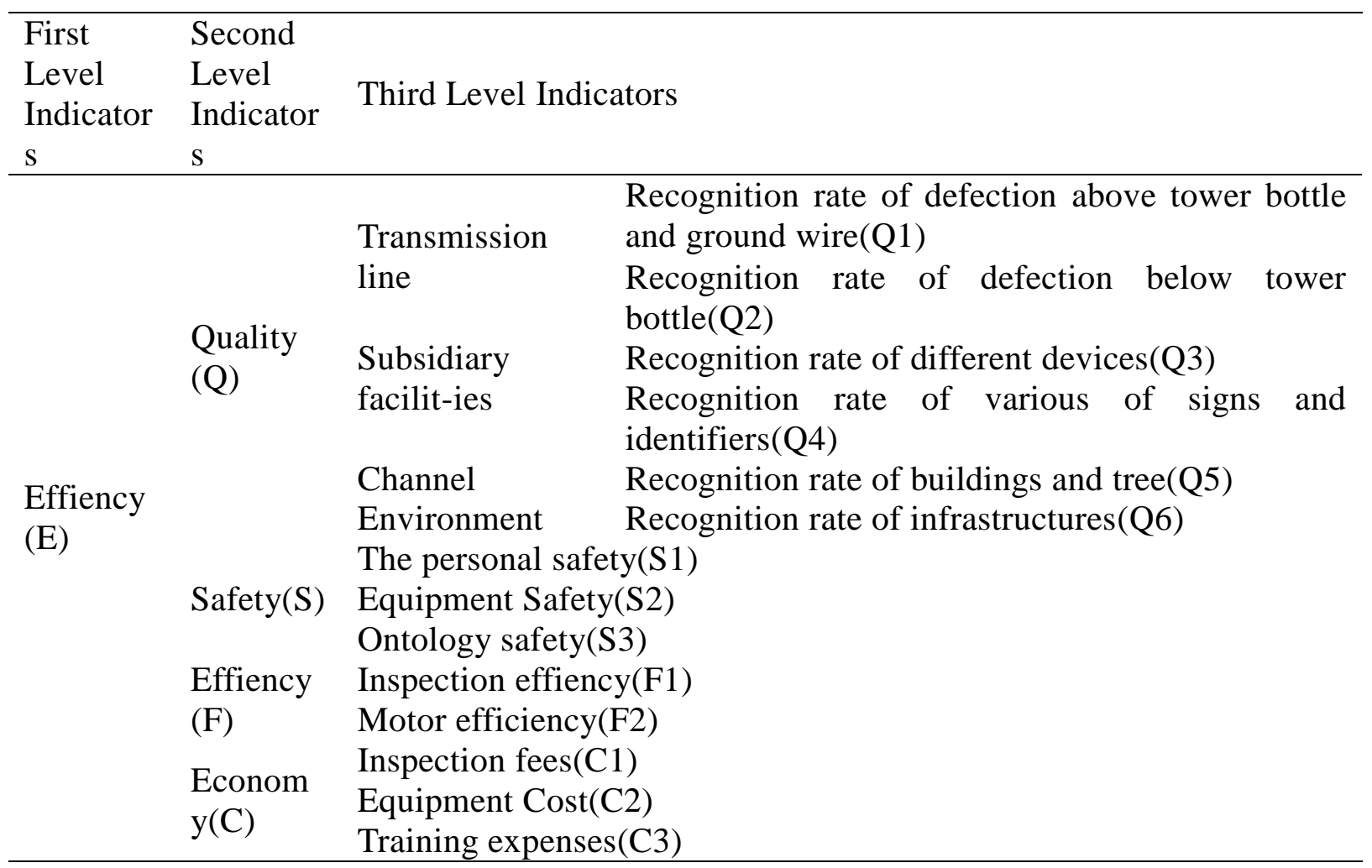

Table 4, below defines each of the indicator in Table 3:

Table 4 The connotation of collaborative inspection evaluation index

\begin{tabular}{|c|c|c|}
\hline & Economic $(\mathrm{C})$ & $\begin{array}{l}\text { One indicator of the four main indicators, evaluated the cost } \\
\text { control levels based on different modes of synthetic inspections of } \\
\text { transmission lines }\end{array}$ \\
\hline \multirow{3}{*}{$\begin{array}{l}\text { Third Level } \\
\text { Indicators }\end{array}$} & $\begin{array}{l}\text { Recognition } \\
\text { rate of } \\
\text { defection } \\
\text { above tower } \\
\text { bottle and } \\
\text { ground wire } \\
\text { (Q1) }\end{array}$ & $\begin{array}{l}\text { Part of quality indicator, inspection recognition rate of guide line, } \\
\text { ground wire, drainage wire, shielded wire, OPGW, line hardware } \\
\text { etc. during synthetic inspections of transmission lines }\end{array}$ \\
\hline & $\begin{array}{l}\text { Recognition } \\
\text { rate of } \\
\text { defection } \\
\text { below tower } \\
\text { bottle } \\
\text { (Q2) }\end{array}$ & $\begin{array}{l}\text { Part of quality indicator, inspection recognition rate of foundation, } \\
\text { cardinal plane, tower base, grounding base, bracing wire, electrical } \\
\text { insulator, etc. during synthetic inspections of transmission lines }\end{array}$ \\
\hline & $\begin{array}{l}\text { Recognition } \\
\text { rate of } \\
\text { different } \\
\text { devices(Q3) }\end{array}$ & $\begin{array}{l}\text { Part of quality indicator, inspection recognition rate of lightning } \\
\text { protection devices, anti-bird devices, various of recognition } \\
\text { devices, aviation warning device, anti-frog \&ice devices, ADSS } \\
\text { optical cablese. During synthetic inspections of transmission lines }\end{array}$ \\
\hline
\end{tabular}




\begin{tabular}{|c|c|c|}
\hline & $\begin{array}{l}\text { Economic }(\mathrm{C} \\
)\end{array}$ & $\begin{array}{l}\text { One indicator of the four main indicators, evaluated the cost control } \\
\text { levels based on different modes of synthetic inspections of } \\
\text { transmission lines }\end{array}$ \\
\hline \multirow{3}{*}{$\begin{array}{l}\text { Third Level } \\
\text { Indicators }\end{array}$} & \begin{tabular}{l}
\multicolumn{2}{l}{ Recognition } \\
rate of \\
various of \\
signs and \\
identifiers \\
$\left(Q^{4}\right)$
\end{tabular} & $\begin{array}{l}\text { Part of quality indicator, inspection recognition rate of tower number, } \\
\text { warning sign, indication sign, phase lag etc. during synthetic inspections } \\
\text { of transmission lines. }\end{array}$ \\
\hline & $\begin{array}{l}\text { Recognition } \\
\text { rate of } \\
\text { buildings } \\
\text { and tree } \\
\text { (Q5) }\end{array}$ & $\begin{array}{l}\text { Part of quality indicator, inspection recognition rate of construction } \\
\text { buildings, illegally planted trees etc. during synthetic inspections of } \\
\text { transmission lines. }\end{array}$ \\
\hline & $\begin{array}{l}\text { Recognition } \\
\text { rate of } \\
\text { infrastructur } \\
\text { es } \\
\text { (Q6) }\end{array}$ & $\begin{array}{l}\text { Part of quality indicator, inspection recognition rate of patrol roads, } \\
\text { bridges, flood prevention, drainage, protection infrastructures etc. during } \\
\text { synthetic inspections of transmission lines. }\end{array}$ \\
\hline \multirow{2}{*}{$\begin{array}{l}\text { Third Level } \\
\text { Indicators }\end{array}$} & $\begin{array}{l}\text { The } \\
\text { personal } \\
\text { safety }(\mathrm{S} 1)\end{array}$ & $\begin{array}{l}\text { The constituent parts of safety index, the probability of personal -injury } \\
\text { during the process of inspection of power transmission line. }\end{array}$ \\
\hline & $\begin{array}{l}\text { Equipment } \\
\text { Safety(S2) }\end{array}$ & $\begin{array}{l}\text { The constituent parts of safety index, the probability of equipment } \\
\text { malfunction during the process of inspection of power transmission } \\
\text { line. }\end{array}$ \\
\hline \multirow[b]{2}{*}{$\begin{array}{l}\text { Third Level } \\
\text { Indicators }\end{array}$} & $\begin{array}{l}\text { Inspection } \\
\text { efficiency }(\mathrm{F} \\
\text { 1) }\end{array}$ & $\begin{array}{l}\text { The constituent parts of safety index, the length of time needed by } \\
\text { various collaborative modes of inspection during the process of } \\
\text { inspection of power transmission line. }\end{array}$ \\
\hline & $\begin{array}{l}\text { Motor } \\
\text { efficiency }(F \\
\text { 2) }\end{array}$ & $\begin{array}{l}\text { The constituent part of efficiency index, the readiness time of various } \\
\text { collaborative modes in preparing for inspecting., i.e. time cost for the } \\
\text { preparatory work of inspection. For example, the air line planning time } \\
\text { and application time of unmanned planes as well as its personnel } \\
\text { scheduling time and machine deployment time. }\end{array}$ \\
\hline \multirow{3}{*}{$\begin{array}{l}\text { Third Level } \\
\text { Indicators }\end{array}$} & $\begin{array}{l}\text { Inspection } \\
\text { fees(C1) }\end{array}$ & $\begin{array}{l}\text { The constituent part of economical index, payments of inspectors' } \\
\text { salary and power expenditure of machines in inspection of power } \\
\text { transmission line. }\end{array}$ \\
\hline & $\begin{array}{l}\text { Equipment } \\
\operatorname{Cost}(\mathrm{C} 2)\end{array}$ & $\begin{array}{l}\text { The constituent part of economical index, acquisition expenses of the } \\
\text { equipment, amortization charge, depreciation cost as well as repair and } \\
\text { maintenance cost, etc. }\end{array}$ \\
\hline & $\begin{array}{l}\text { Training } \\
\text { expenses }(\mathrm{C} \\
\text { 3) }\end{array}$ & $\begin{array}{l}\text { The constituent part of economical index, expenses of technician } \\
\text { training programs. }\end{array}$ \\
\hline
\end{tabular}

\section{Conclusion}

Based on the analysis of influencing factors of the cost-efficiency of synthetic inspections and the research on the assessment of the indicator system, this paper analyzes the current situation of the synthetic inspections of transmission lines in China's power grid system. After reviewing the 
literature and theoretical research on manual inspection, helicopter inspection and unmanned aerial inspection of transmission lines at home and abroad, consulting power grid experts and analyzing the features of different inspection models and the influencing factors of the cost-efficiency of synthetic inspections, this research has extracted, distinguished and classified the influencing factors. These factors influencing synthetic inspections can be classified into four major categories - terrain, climate, inspected objectives and seasonal conditions. Indicators that assess the cost-efficiency of synthetic inspections are selected and clearly defined.

\section{References}

[1] H. Zhang. The state of overhead transmission line operation and maintenance management research [D].North China Electric Power University, 2012.

[2] G.X.LI. Current situation and development of helicopter power operation in China [J]. electric power equipment, 2006, 7 (3): 41 45

[3] X.B. Cen, Y.L. Ma and Z.J. Xu. Study on transmission line inspection technology of unmanned aerial vehicle (Southern Power Grid Technology.2008, 2 (6):57 60.

[4] P. Wang, G. Li and K. Zhu, et al. Study on the application of the transmission line in the transmission line $[\mathrm{J}]$. Sichuan electric power technology, 2002, 4 6. 1:

[5] Y.P. Xu, Q. Mao and T.J .Li. The research and Study on the complementary mechanism of helicopter, unmanned aerial vehicle and ground manual inspection of overhead transmission line [J], Guangxi electric power, 2013, 05:72 75

[6] Whitworth C C, Duller A W G, Jones D I, et al. Aerial video inspection of overhead power lines [J]. Power Engineering Journal, 2001, 15 (1): 25 32.

[7] M. Bai. General aviation operation and future development trend of foreign countries [J]. integrated transport, 2001, (1):30 31.

[8] Jaensch G, Hoffmann H, Markees A. Locating defects in high voltage transmission lines. Proceedings of the 1998 IEEE 8th International Conference on Transmission Distribution Construction, Operation \& Live-line Maintenance. Orlando, FLUSA: 1998. 179 186.

[9] Cambone S.A., Krieg K.J., Pace P. Unmanned Aerial Systems Road map 2005 2030. Washington DC: Office of the Secretary of Defense, 2005.

[10]J. Li, W.J. Li, K. Xiao and J.G. Liang: Power communication device state evaluation method based on fuzzy comprehensive evaluation [J] Southern Power System Technology, 2014, 05:56-60. 